\title{
Employing RMR Technology in a 90-Day Weight Control Program
}

\author{
Scott O. McDoniel ${ }^{\mathrm{a}}$ Heather A. Nelson ${ }^{\mathrm{b}}$ Cynthia A. Thomson ${ }^{\mathrm{c}}$ \\ ${ }^{a}$ Harold Abel School of Psychology; Capella University, Minneapolis, MN, \\ ${ }^{b}$ Air Command and Staff College, Air University, Maxwell AFB, AL, \\ ${ }^{c}$ Department of Nutritional Sciences, University of Arizona, Tucson, AZ, USA
}

\section{Key Words}

Weight loss - Diet therapy · Obesity · Overweight . Indirect calorimetry - MedGem · Metabolism . Energy balance

\section{Summary}

Objective: The purpose of this study was to evaluate the efficacy of a weight management program using indirect calorimetry to set energy goals. Methods: 54 overweight, active duty adult employees of the US Air Force (age 18-46 years, BMI $25.2-35.6 \mathrm{~kg} / \mathrm{m}^{2}$ ) participated in this quasi-experimental control design study. All participants were enrolled in a four-session US Air Force 'Sensible Weigh' group weight control program. Treatment participants received a personalized nutrition energy goal message developed using measured resting metabolic rate (RMR) from a hand-held indirect calorimeter (MedGem ${ }^{\circledR}$ ). Usual care participants received a nutritional message using a standard care equation $(25 \mathrm{kcal} / \mathrm{day} \times$ body weight) to set energy intake goals. Results: Treatment participants lost significantly more weight than usual care participants $(p \leq 0.05)$. Difference in weight loss between the treatment and usual care group were $-4.3 \mathrm{~kg} \pm$ 3.3 vs. $-1.8 \mathrm{~kg} \pm 3.2$, respectively. There were no significant differences in reported food intake or energy expenditure between groups. Conclusion: The use of indirect calorimetry to assess RMR and set energy intake goals positively influences weight loss success in overweight Air Force personnel.

\section{Introduction}

The prevalence of overweight and obesity is rising in the US population, with $34.1 \%$ of the US population being overweight and $32.2 \%$ obese [1]. It is estimated that $75 \%$ of US adults will be overweight or obese by 2015 [2]. The current epidemic of overweight and obesity is also apparent among US Air Force personnel with overweight at $44.4 \%$ (men = $47.9 \%$, women $=29.9 \%)$ and obesity at $12.4 \%($ men $=13.8 \%$, women $6.4 \%$ ) [3]. The direct costs (increased medical care) and indirect costs (lost workdays) of excess body weight are high among active duty Air Force personnel. It is estimated that the direct costs associated with overweight or obese Air Force personnel are USD 19.3 million per year and indirect costs (i.e. increased medication use, sick days, ) are USD 3.5 million per year [4].

Due to the potential health and economic impact of overweight status on Air Force personnel, the Air Force instituted a weight management program until January 2004 to help overweight Air Force personnel obtain and maintain body weight that meets standards for health, physical readiness, and military appearance [5]. At the time of the study, Air Force personnel received official weight and height measurements at least annually. Those who exceeded Air Force weight standards had their body fat percentage measured using a circumferential measurement technique with a Gulick tape measure. The Air Force maximum body fat standards for men are $20 \%$ for those aged 18-29 years and 24\% for those over 30 years. Maximum allowable body fat standards for women are $28 \%$ for those aged 18-29 years and 32\% for those over 30 years [6]. Personnel with measurements exceeding these limits were required to enroll in a 90-day intervention program to reduce body weight and body fat [6]. One component of the weight loss program is nutritional assessment. Prior to adopting the now recommended energy assessment equation by the Amer-

\begin{tabular}{ll}
\hline KARGER & $\oplus$ 2008 S. Karger GmbH, Freiburg \\
Fax +497614520714 & Accessible online at: \\
$\begin{array}{l}\text { Information@Karger.de } \\
\text { www.karger.com }\end{array}$ & www.karger.com/ofa
\end{tabular}


ican Dietetic Association (i.e. Mifflin-St. Jeor Equation) [7, 8], the Air Force employed the estimated equation recommended by the American College of Chest Physicians (ACCP) [9] and European Clinical Practice Guidelines for adult obesity management [10]. These estimations often use basic demographic information (age, height, weight, and gender) to determine daily energy needs. Recently, research has indicated that many of the equations are significantly inaccurate in large numbers of obese, overweight, and normal-weight individuals [7]. Because of these significant inaccuracies, the American Dietetic Association has issued clinical guidelines for assessment of nutritional needs and recommends the use of indirect calorimetry, if available, instead of estimation equations in establishing caloric goals in adult weight management programs [11].

Although the American Dietetic Association recommends the use of indirect calorimetry as the preferred standard for nutritional assessment, little is known if employing the use of indirect calorimetry as opposed to traditional equation-based estimates is more effective in inducing weight loss in the context of weight loss intervention programs. Due to the lack of empirical support substantiating the use of indirect calorimetry over traditional equations, this study sought to determine if implementing indirect calorimetry measures of energy intake goals as part of the Air Force weight management program is efficacious for promoting weight loss in active duty Air Force personnel.

\section{Material and Methods}

This study was a 90-day quasi-experimental control trial using a purposeful sample of US Air Force personnel. All participants were recruited from a diet and exercise class at a US Air Force Base. Participants were selected to participate in the study if they were active duty Air Force personnel who exceeded both Air Force body weight and fat standards, medically cleared to enter a weight loss program, and had a body mass index (BMI) greater than $25 \mathrm{~kg} / \mathrm{m}^{2}$. Individuals were excluded from the study if they had been previously diagnosed with type I diabetes mellitus, bulimia nervosa, were pregnant or lactating, or were scheduled for deployment within 3 months from the start of the study.

Once individuals met the inclusion criteria for the study and provided consent to participate, each individual was randomly assigned to one of two groups (experimental or usual care). Experimental participants received a resting metabolic rate (RMR) assessment using a hand-held indirect calorimeter $\left(\right.$ MedGem ${ }^{\circledR}$; Microlife Medical Home Solutions, Inc., Golden, CO, USA). Participants were instructed to abstain from food, beverage (except water), caffeine, tobacco, and alcohol for $4 \mathrm{~h}$ prior to the RMR measurement as indicated by the manufacturer. Participants also abstained from strenuous physical activity for $4 \mathrm{~h}$. Prior to the test, subjects rested in a semi-recumbent position for $15 \mathrm{~min}$. The hand-held device automatically turns off at the conclusion of the measurement and displays the participant's RMR on the device display screen. The measurement time was approximately $10 \mathrm{~min}$ in length. A recent systematic review of all MedGem validation studies indicate the MedGem to be an accurate and reliable indirect calorimeter for assessing RMR in healthy overweight individuals [12].

A registered dietitian informed intervention participants of personal RMR results. In addition, participants received an educational handout 'What Affects My Resting Metabolic Rate.' Total energy expenditure
(TEE) was established by the following algorithm $(\mathrm{RMR} \times 1.25=\mathrm{TEE}$ (kcal/day)). RMR was multiplied by the metabolic equivalency (METS) of 1.25 based on previous research indicating RMR accounts up to $75 \%$ of TEE in most individuals [13]. A personalized caloric goal was established by reducing TEE by $250-500 \mathrm{kcal} /$ day to facilitate a $0.45-0.91 \mathrm{~kg} /$ week weight loss.

Usual care participants received a nutrition program based on estimated, rather than measured, energy expenditure $(25 \times$ baseline body weight (kg)) [9] and subtracting 250-500 kcal/day to promote a $0.45-0.91$ $\mathrm{kg} /$ week weight reduction. All study participants participated in the foursession Air Force 'Sensible Weigh' group weight control program that was led by a dietitian or certified diet therapy technician. Core topics within the group program included basic nutrition, self-monitoring of food intake and exercise, physical activity, and behavior modification [14].

Anthropometric (i.e. weight, height, BMI, and percent body fat) measurements were measured at baseline and 90 days using Air Force approved circumferential measurements. Energy intake and energy expenditure was estimated from the Arizona Food Frequency Questionnaire (AFFQ) and Arizona Activity Frequency Questionnaire (AAFQ), respectively at baseline and 90 days. When compared to 24-hour dietary recall and the 4-day food record, the AAFQ has high validity and reliability $(r=0.53$ and $r=0.49)[15,16]$. The AAFQ was validated against doubly labeled water, and results $\left(r^{2}=0.70\right)$ indicate the AAFQ to be an accurate measure for physical activity energy expenditure [17].

Statistical analysis was conducted with the Statistical Package for the Social Sciences (SPSS 13.0) (SPSS, Inc. Chicago, IL, USA). A factorial analysis of variance (ANOVA) was used to determine if the means of completers were significantly different between the two study groups over time. Intent-to-treat analysis was conducted on all randomized participants using the last observation carried forward (LOCF) method. Statistical significance was set at $\mathrm{p} \leq 0.05$.

We certify that all applicable institutional and governmental regulations concerning the ethical use of human volunteers were followed during this research study. The protocol received approval from the institutional review board (IRB) at the Wilford Hall Medical Center, Lackland Air Force Base. Standard consent procedures were utilized prior enrollment into the study.

\section{Results}

54 (36 males, 18 females) adult Air Force employees participated in the study. 25 usual care individuals and 19 experimental individuals completed the 90-day weight control program ( $18 \%$ attrition). The average age of the study participants was $28.0 \pm 7.3$ years (range 18-46 years). Average weight and BMI of the study participants were $90.5 \pm 14.4 \mathrm{~kg}(65-124.1 \mathrm{~kg})$ and $29.8 \pm 2.4 \mathrm{~kg} / \mathrm{m}^{2}\left(25.2-35.6 \mathrm{~kg} / \mathrm{m}^{2}\right)$, respectively. Baseline weight and BMI of men $\left(98.0 \pm 10.5 \mathrm{~kg}\right.$ and $\left.30.7 \pm 1.8 \mathrm{~kg} / \mathrm{m}^{2}\right)$ and women $\left(75.5 \pm 7.8 \mathrm{~kg}\right.$ and $\left.27.8 \pm 2.1 \mathrm{~kg} / \mathrm{m}^{2}\right)$ were significantly different $(\mathrm{p} \leq 0.05)$. There were no significant differences in body weight, body fat, or BMI between groups prior to the study intervention.

Ten participants did not complete the program: One was discharged from the Air Force, two became pregnant, and seven obtained medical waivers from participating in the program or the commanding unit did not appropriately schedule the 90-day follow-up appointment. The average age, BMI, body weight, and body fat of non-completers was $26.1 \pm 5.2$ years (19-37 years), $28.6 \pm 2.2 \mathrm{~kg} / \mathrm{m}^{2}\left(25.9-33.1 \mathrm{~kg} / \mathrm{m}^{2}\right), 84.0 \pm 11.5$ 
Fig. 1. Individual response to weight change of individuals completing the 90-day program $(\mathrm{n}=44)$. Overall, the group lost an average of $3.1 \%$ body weight.

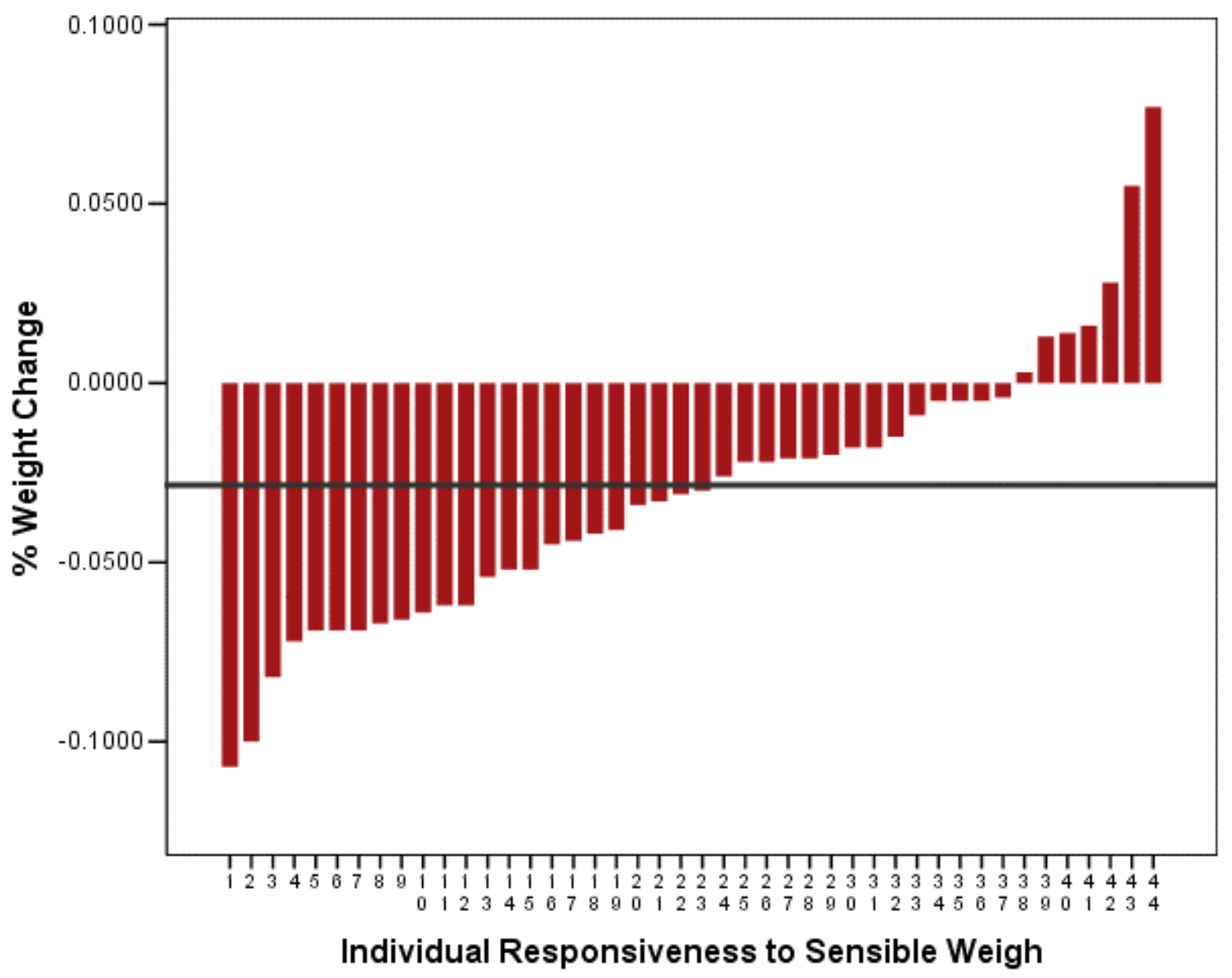

Table 2. Descriptive statistics for completers

Table 1. Descriptive statistics ITT-LOCF

\begin{tabular}{lll}
\hline & \multicolumn{2}{l}{ Study group } \\
\cline { 2 - 3 } & $\begin{array}{l}\text { experimental } \\
(\mathrm{n}=25)\end{array}$ & $\begin{array}{l}\text { usual care } \\
(\mathrm{n}=29)\end{array}$ \\
\hline Baseline weight, $\mathrm{kg}$ & $91.5 \pm 14.5$ & $89.7 \pm 14.5$ \\
Post weight, $\mathrm{kg}$ & $88.3 \pm 13.4^{\mathrm{a}}$ & $88.1 \pm 14.8$ \\
Baseline BMI, $\mathrm{kg} / \mathrm{m}^{2}$ & $29.9 \pm 2.3$ & $29.6 \pm 2.4$ \\
Post BMI, $\mathrm{kg} / \mathrm{m}^{2}$ & $28.9 \pm 2.2$ & $29.2 \pm 2.7$ \\
Baseline body fat, \% & $29.7 \pm 4.7$ & $29.0 \pm 5.0$ \\
Post body fat, \% & $25.8 \pm 5.0$ & $28.2 \pm 5.8$ \\
\hline
\end{tabular}

aSignificantly different between groups $(\mathrm{p} \leq 0.05)$.

$\mathrm{kg}(70.5-98.6 \mathrm{~kg})$, and $29.3 \pm 4.3 \%(22-35 \%)$, and the baseline values were not significantly different from completers.

Intent-to-treat analysis using the LOCF indicate the 'Sensible Weigh' program resulted in clinically minimal yet significant reductions in body weight $(-2.3 \pm 3.2 \mathrm{~kg} ; \mathrm{p} \leq 0.05$ (95\% CI -1.4 to $-3.3 \mathrm{~kg})$ ) body fat $(-1.7 \pm 2.4 \% ; \mathrm{p} \leq 0.05$ (95\% CI; -1.0 to $-2.3 \%)$ ), and BMI (0.45-0.90 kg/week $(-0.80 \pm 1.1 ; \mathrm{p} \leq 0.05$ (95\% CI: -0.5 to $\left.-1.1 \mathrm{~kg} / \mathrm{m}^{2}\right)$ ). Individual response to weight reduction is presented in figure 1.

\begin{tabular}{lll}
\hline & Study group & \\
\cline { 2 - 3 } & $\begin{array}{l}\text { experimental } \\
(\mathrm{n}=19)\end{array}$ & $\begin{array}{l}\text { esual care } \\
(\mathrm{n}=25)\end{array}$ \\
\hline Baseline weight, $\mathrm{kg}$ & $94.7 \pm 14.3$ & $89.8 \pm 14.9$ \\
Post weight, $\mathrm{kg}$ & $90.6 \pm 13.6^{\mathrm{a}}$ & $88.0 \pm 15.3$ \\
Baseline BMI, $\mathrm{kg} / \mathrm{m}^{2}$ & $30.4 \pm 2.4$ & $29.8 \pm 2.4$ \\
Post BMI, $\mathrm{kg} / \mathrm{m}^{2}$ & $29.0 \pm 2.3^{\mathrm{a}}$ & $29.2 \pm 2.7$ \\
Baseline body fat, \% & $27.9 \pm 5.0$ & $29.2 \pm 5.0$ \\
Post body fat, \% & $25.1 \pm 4.8$ & $27.7 \pm 6.0$ \\
\hline
\end{tabular}

aSignificantly different between groups $(\mathrm{p} \leq 0.05)$.

Intent-treat analysis demonstrated significant difference in weight loss between groups $(-3.3 \pm 3.4$ vs. $-1.5 \pm 3.0 \mathrm{~kg}$; $\mathrm{p} \leq 0.05)$. Descriptive statistics using ITT-LOCF are presented in table 1. Completer analysis indicated the experimental group lost significantly more weight than the control group $(-4.3 \pm 3.3$ vs. $-1.8 \pm 3.2 \mathrm{~kg} ; \mathrm{p} \leq 0.05)$. Descriptive statistics for completers are presented in table 2. Within the intervention group, $42 \%$ (n $=8$ ) of the participants achieved or exceeded $5 \%$ weight loss compared to $28 \%(\mathrm{n}=7)$ of the control participants (fig. 2). 
Fig. 2. Individual response to weight change by treatment group.

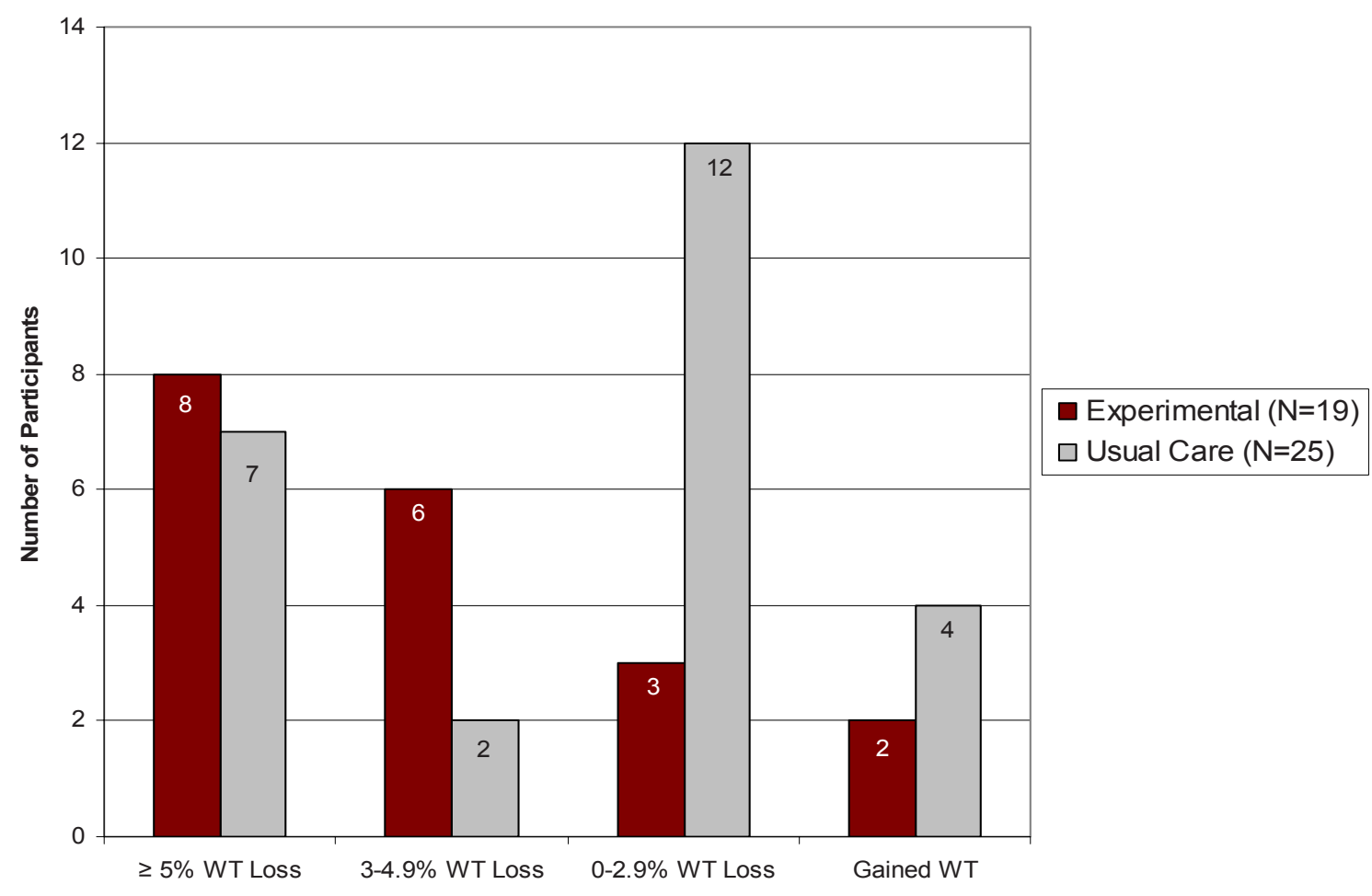

Table 3. Baseline descriptive statistics of dietary intake and physical activity

\begin{tabular}{lll}
\hline & \multicolumn{2}{l}{ Study group } \\
\cline { 2 - 3 } & $\begin{array}{l}\text { experimental } \\
(\mathrm{n}=18)\end{array}$ & $\begin{array}{l}\text { usual care } \\
(\mathrm{n}=21)\end{array}$ \\
\hline Calories, kcal/day & $2,648 \pm 1,789$ & $2,307 \pm 928$ \\
Cholesterol, mg & $354.5 \pm 312$ & $250.4 \pm 107$ \\
Carbohydrates, \% & $52.8 \pm 10.2$ & $53.4 \pm 7.2$ \\
Fat, \% & $31.9 \pm 6.9$ & $32.5 \pm 5.9$ \\
Protein, \% & $15.7 \pm 3.3$ & $16.0 \pm 3.3$ \\
\cline { 2 - 3 } & $\begin{array}{l}\text { experimental } \\
(\mathrm{n}=17)\end{array}$ & $\begin{array}{l}\text { usual care } \\
(\mathrm{n}=20)\end{array}$ \\
\cline { 2 - 3 } & $632 \pm 534$ & $341 \pm 259$ \\
\hline
\end{tabular}

Completer analysis was available for food intake and physical activity expenditure. 21 usual care and 18 experimental participants completed baseline and post-treatment questionnaires. There were no significant differences in baseline dietary intake across groups. However, the experimental group reported a trend toward significantly greater energy expenditure related to physical activity, at baseline, compared to the usual care group $(291 \pm 148 \mathrm{kcal} /$ day; $\mathrm{p}=0.06)$. Baseline descriptive statistics are presented in table 3 . Overall, there was a significant reduction in total calorie intake $(-729 \pm 1,047 \mathrm{kcal} / \mathrm{day} ; \mathrm{p} \leq$ $0.05)$ and a strong trend for reducing dietary cholesterol levels $(-62.9 \pm 217.2 \mathrm{mg} / \mathrm{day} ; \mathrm{p}=0.08)$ following the 90 -day program
Table 4. Post-treatment descriptive statistics of dietary intake and physical activity

\begin{tabular}{lll}
\hline & \multicolumn{2}{l}{ Study group } \\
\cline { 2 - 3 } & $\begin{array}{l}\text { experimental } \\
(\mathrm{n}=18)\end{array}$ & $\begin{array}{l}\text { usual care } \\
(\mathrm{n}=21)\end{array}$ \\
\hline Calories, kcal/day & $1,653 \pm 1257$ & $1,805 \pm 981$ \\
Cholesterol, mg & $251.9 \pm 242.6$ & $221.2 \pm 146.9$ \\
Carbohydrates, \% & $52.6 \pm 13.0$ & $54.8 \pm 12.6$ \\
Fat, \% & $31.0 \pm 5.8$ & $30.1 \pm 9.6$ \\
Protein, \% & $16.7 \pm 4.2$ & $16.9 \pm 3.2$ \\
\cline { 2 - 3 } & $\begin{array}{l}\text { experimental } \\
(\mathrm{n}=17)\end{array}$ & $\begin{array}{l}\text { usual care } \\
(\mathrm{n}=20)\end{array}$ \\
\cline { 2 - 3 } Physical activity, kcal/day & $540 \pm 459$ & $454 \pm 338$ \\
\hline
\end{tabular}

although there was no significant difference in the change in these intakes between groups. There was no significant change in physical activity expenditure over time or between groups. Post-treatment descriptive statistics for food intake and energy expenditure are presented in table 4.

\section{Discussion}

The Air Force is facing a similar rise in the incidence of obesity that is also a significant health issue for the US population. Effective programs are needed to minimize weight gain and 
promote weight reduction. This study was the first of its kind evaluating the efficacy of the Air Force 'Sensible Weigh' group weight control program. Results from this study indicate the program has a minimal, yet significant effect on weight loss, BMI, and body fat ( $\mathrm{p} \leq 0.05)$. The 'Sensible Weigh' program appears to be efficacious for short-term weight loss (90 days), resulting in a clinically meaningful body weight loss of $-3.1 \pm 3.8 \%$. Though the program is 90 days, it would be beneficial for the US Air Force to lengthen the program to possibly promote greater weight loss. Current guidelines recommend a $5-10 \%$ weight reduction over a 6 -month period [18], and by adjusting the program (i.e. include additional educational sessions over an additional time period) the participants may be able to obtain the recommended weight loss goal. In addition, future studies are needed to determine the long-term efficacy of the 'Sensible Weigh' program.

The use of indirect calorimetry to estimate caloric needs and establish caloric intake goals for weight loss as part of the 'Sensible Weigh' program was shown to be significantly more effective in short-term weight loss than using the ACCP equation ( $\mathrm{p} \leq 0.05)$. From the completer analysis, $75 \%$ of the intervention participants $(\mathrm{n}=14)$ achieved a level of weight loss $(3 \%)$ that would have health benefits $[19,20]$ compared to $36 \%(n=9)$ in the control group. Thus, the use of indirect calorimetry did result in improved individual responsiveness to the weight loss program as compared to using estimation equations (fig. 2).

It was difficult to ascertain if measured RMR resulted in a significant change in eating behaviors as measured by the AFFQ. Both groups experienced a significant reduction in self-reported caloric intake but the results were highly variable and were not significantly different between groups over time. In fact, repeat measurements of dietary intake using food frequency questionnaires in the context of diet intervention trials commonly results in reduced energy and total food intake over time. Further, self-report measures of food intake with food frequency questionnaires and food records are regularly inaccurate [21-23]. Since self-report of food intake values can be variable and inaccurate, future studies should consider assessing eating behaviors (i.e. cognitive restraint, hunger, emotional eating, etc.) in addition to calorie intake. Assessments that measure dietary cognitive restraint are highly correlated with high-fat calorie-dense foods [24-26]. Therefore, future studies might consider investigating if measured RMR has an influence on dietary cognitive restraint versus calorie intake values. Measured RMR had no effect on physical activity or exercise behavior according to the results from the AAFQ. Previous research has routinely demonstrated that most weight control participants will reduce calorie intake levels versus increasing physical activity [27]. In this study, it appears individuals preferentially decreased calorie intake values over increasing the level of physical activity. However, our study participants, routinely participate in exercise at the recommended values (30-60 min/day), resulting in mean daily energy expenditure from physical activity that exceeded $500 \mathrm{kcal} /$ day. Since these participants were already active, it appears the focus for both groups was calorie reduction.

Since the experimental group lost significantly more body weight following the 90-day weight loss program than the usual care group, the researchers hypothesized the ACCP algorithm $(25 \times$ baseline body weight $(\mathrm{kg})-(250-500 \mathrm{kcal}))$ may overestimate the daily needs of usual care participants. Administering a total of $25 \mathrm{kcal} / \mathrm{day} / \mathrm{kg}$ body weight appears to be adequate for estimating daily calorie needs $[9,10]$. However, it is not known if this consensus recommendation is only for patients with major medical illnesses. Cerra et al. [9] did indicate additional calories may be needed for patients with certain medical conditions. For example, individuals that have systemic inflammatory response syndrome, with or without multiple organ dysfunction syndrome, may need to increase total calorie requirements by $10-20 \%$. Clearly, the prospective study participants were not hospitalized and were clear from any major illnesses. As a result there was no indication for further increasing calories when designing the recommended nutritional plans. However, a post-hoc analysis indicated the ACCP algorithm, before the 250-500 kcal reduction, significantly underestimated daily calorie needs by $-247 \pm 230$ $\mathrm{kcal} /$ day $(95 \% \mathrm{CI}$ : -341 to $-151 \mathrm{kcal} /$ day $)(\mathrm{p}=0.00)$ in experimental participants. If the ACCP equation underestimates daily calorie needs for weight loss, then why did the usual care group not lose significantly more body weight?

A possible reason why experimental individuals experienced greater weight loss from measured RMR may be that the individualized nutrition message influenced psychobehavioral constructs (i.e. motivation, self-efficacy, etc.) for weight loss change. Tailored messages that are specific to an individual are more effective in promoting health behavior adoption than general population-based information [28]. In a recent metaanalysis consisting of 40 studies comparing a tailored message versus a general message for various health behavior topics (i.e. diet, exercise, smoking cessation. etc), results demonstrate a positive effect on health behavior change. More specifically, a tailored message specific to the characteristic of the individual versus a general message influences diet and exercise behavior change with an odds ratio (OR) of 1.05-1.10 [28]. A post-hoc analysis of our study was conducted, and the results were similar $(\mathrm{OR}=1.10)$. As noted by Noar et al. [28] tailored messages have the advantage of being individually customized to increase the chance that the message will be viewed as personally relevant and credible, thereby persuading the individual. Previous research has indicated that the average overweight individual has attempted weight loss approximately 1-2 times per year $[29,30]$. If a weight loss-seeking individual previously attempted a similar nutrition program, as recommended by the guidelines, then it is possible that the calorie level is less persuasive and less credible, thereby discounting the potential motivational affect to pursue weight loss. As a result, the RMR measurement from indirect calorimetry may 
be viewed as more credible and personally relevant, thereby persuading the individual that weight loss can be achieved. This theoretical explanation is also consistent from previous studies, demonstrating tailored messages are more likely to be understood, recalled, rated highly, and perceived as credible $[31,32]$. To validate this theory, future research should evaluate if using technology in weight reduction programs influences key psychobehavioral constructs (i.e. motivation, self-efficacy, etc.) that facilitate behavior adoption.

There are some limitations to this study. First, the study was only 90 days in length, and there was no follow-up beyond the intervention period. Therefore, it is not known if the intervention or usual care groups were able to maintain weight loss. Future research is needed to determine the long-term efficacy of using indirect calorimetry as part of a comprehensive weight control program. Second, at the time of the study, the Air Force had regulations that all personnel maintain a desired body weight and body fat percentage, or these individuals could be discharged from service [6]. To this end, the participants may have had an additional incentive to achieve weight loss than civilian counterparts, although this motivational factor would have existed in both groups and generally the degree of weight loss was not as clinically relevant as was expected. Further, the sample size and the treatment effect were small $(\mathrm{d}=0.10)$. Moreover, since weight loss is the result of negative energy balance by way of reduced food intake and/or increased physical activity, the small sample size may be a limitation to why we were unable to detect a significant difference between groups. Therefore, one might conclude that using RMR technology has relative applicability if only a small effect is noted and such a large sample size is needed to determine if absolute caloric intake and energy expenditure are different from usual practices. However, the current status of the weight loss programs on long-term efficacy is dismal, with $\leq 20 \%$ individuals maintaining weight loss and most will return to pre-treatment body weight $[33,34]$. Although the treatment effect is small, the individual responsiveness to weight change is clinically acceptable. Moreover, patients desire individualized treatment in place of standardized programming [35]. Therefore, the use of RMR technology provides an opportunity to more accurately provide an individualized nutrition plan, fulfilling patients' request and potentially influencing motivation.

In conclusion, the 'Sensible Weigh' program is minimally effective for short-term weight loss. Although the participants did significantly reduce body weight following the program, overall weight loss results were not at the level of recommended standards (i.e. 5-10\% weight reduction within 6 months) [18]. Employing a hand-held indirect calorimeter as part of the program does generate significantly greater weight loss as compared to the use of the ACCP estimation equation. The weight loss results in the intervention group were closer to the Air Force standard (0.45-0.91 kg/week weight reduction) [6]. Weight loss that results from a program using indirect calorimetry technology may be enhanced by tailored nutritional messaging based on an individual's metabolic response. Future research is needed to validate these results and expand the literature to better understand how measured RMR influences psychobehavioral constructs for weight behavior change. Based on these data, the use of RMR technology demonstrates promise for effective weight loss outcomes.

\section{Implications for Practice}

Personalizing a nutritional message for weight loss-seeking adults is more influential on the weight loss behavioral change process than standardized recommendations [28]. Clinicians can tailor a nutritional message from specific physiological parameters. The use of RMR measurement devices may provide clinicians a diagnostic tool for tailoring a nutrition message specific to each client. Similar to other physiological parameters (i.e. cholesterol, blood pressure, glucose, etc.) that some clients would need to know to better manage a disease, the use of RMR technology would provide a parameter (i.e. daily caloric intake goal) that may empower a client to better manage body weight. By personalizing a nutrition program, clients may be more motivated and have greater confidence with weight management.

\section{Acknowledgements}

The authors would like to acknowledge Lt Col Nancy Klein, USAF, and the staff at the Health and Wellness Center at Davis-Monthan Air Force Base for their assistance with this study.

\section{Disclosure}

The senior author, Scott O. McDoniel, is employed with Microlife Medical Homes Solutions, Inc.

\section{References}

1 Ogden CL, Carroll MD, Curtin LR, McDowell MA, Tabak CJ, Flegal KM: Prevalence of overweight and obesity in the United States, 1999-2004. JAMA 2006;295:1549-1555.

2 Wang Y, Beydoun MA: The obesity epidemic in the United States- gender, age, socioeconomic, racial/ ethnic, and geographic characteristics: a systematic review and meta-regression analysis. Epidemiol Rev 2007;29:6-28.
3 USAF: ASIMS/AFCHIPS Process Monitoring. United States Air Force, https://www.afchips. brooks.af.mil/main/main.aspx (accessed October 30, 2007).

4 Research CoMN: Weight Management: State of the Science and Opportunities for Military Programs. Washington, DC, Institute of Medicine of the National Academies, 2003

\footnotetext{
5 Atkinson RL, Vanderveen JE, Dietz WH, Fernstrom JD, Frank A, Hansen BC, Heymsfield SB, Kanarek RB, Moore BJ: Weight Management: State of the Science and Opportunities for Military Programs. Washington D.C., National Academy of Sciences, 2003.

6 Air Force Instruction 40-502: The Weight and Body Fat Management Program. 2002
} 
7 Frankenfield D, Roth-Yousey, Compher C: Comparison of predictive equations for resting metabolic rate in healthy nonobese and obese adults: a systematic review. J Am Diet Assoc 2005;105:775-789.

8 Compher C, Frankenfield D, Keim N, Roth-Yousey $\mathrm{L}$ : Best practice methods to apply to measurement of resting metabolic rate in adults: a systematic review. J Am Diet Assoc 2006;106:881-903.

9 Cerra FB, Benitez MR, Blackburn GL, Irwin RS, Jeejeebhoy K, Katz DP, Pingleton SK, Pomposelli J, Rombeau JL, Shronts E, Wolfe RR, Zaloga GP: Applied nutrition in ICU patients. A consensus statement of the American College of Chest Physicians. Chest 1997;111:769-778.

10 Tsigos C, Hainer V, Basdevant A, Finer N, Fried M, Mathus-Vliegen E, Micic M, Roman G, Schutz Y, Toplak H, Zahorska-Markiewicz B: Management of obesity in adults: European clinical practice guidelines. Obesity Facts 2008;1:106-116.

11 ADA: Adult Weight Management Evidence-Based Nutrition Practice Guideline. Chicago, American Dietetic Association, 2006.

12 McDoniel S: A systematic review on the accuracy and reliability of a hand-held indirect calorimeter for assessing energy needs in adults and children. Int J Sport Nutr Exerc Metab 2007;17:491-500.

13 Danforth E Jr: Dietary-induced thermogenesis: control of energy expenditure. Life Sci 1981;28: 1821-1827.

14 Spahn L: Air Force: The Sensible Weigh Leader's Guide. United States Air Force, 1998, vol 2003.

15 Thomson CA, Giuliano A, Rock CL, Ritenbaugh CK, Flatt SW, Faerber S, Newman V, Caan B, Graver E, Hartz V, Whitacre R, Parker F, Pierce JP, Marshall JR: Measuring dietary change in a diet intervention trial: comparing food frequency questionnaire and dietary recalls. Am J Epidemiol 2003; 157:754-762.

16 Martinez ME, Marshall JR, Graver E, Whitacre RC, Woolf K, Ritenbaugh C, Alberts DS: Reliability and validity of a self-administered food frequency questionnaire in a chemoprevention trial of adenoma recurrence. Cancer Epidemiol Biomarkers Prev 1999;8:941-946.
17 Staten LK, Taren DL, Howell WH, Tobar M, Poehlman ET, Hill A, Reid PM, Ritenbaugh C: Validation of the Arizona Activity Frequency Questionnaire using doubly labeled water. Med Sci Sports Exerc 2001;33:1959-1967.

18 National Institutes of Health: Practical Guide to the Identification, Evaluation, and Treatment of Overweight and Obesity in Adults. Bethesda, National Institutes of Health, National Heart, Lung, and Blood Institute, North American Association for the Study of Obesity, 2000.

19 Diabetes Prevention Program Research Group: Reduction in the incidence of type 2 diabetes with lifestyle intervention or metformin. N Engl J Med 2002;346:393-403.

20 Klein S, Burke LE, Bray GA, Blair S, Allison DB, Pi-Sunyer X, Hong Y, Eckel RH: Clinical implications of obesity with specific focus on cardiovascular disease: a statement for professionals from the American Heart Association Council on Nutrition, Physical Activity, and Metabolism: endorsed by the American College of Cardiology Foundation. Circulation 2004;110:2952-2967.

21 Molag ML, de Vries JH, Ocke MC, Dagnelie PC, van den Brandt PA, Jansen MC, van Staveren WA, van't Veer P: Design characteristics of food frequency questionnaires in relation to their validity. Am J Epidemiol 2007;166:1468-1478.

22 Schaefer EJ, Augustin JL, Schaefer MM, Rasmussen H, Ordovas JM, Dallal GE, Dwyer JT: Lack of efficacy of a food-frequency questionnaire in assessing dietary macronutrient intakes in subjects consuming diets of known composition. Am J Clin Nutr 2000;71:746-751.

23 Scagliusi FB, Polacow VO, Artioli GG, Benatti FB, Lancha AH Jr: Selective underreporting of energy intake in women: magnitude, determinants, and effect of training. J Am Diet Assoc 2003;103: 1306-1313.

24 Blandine de Lauzon, Romon M, Deschamps V, Lafay L, Borys J-M, Karlsson J, Ducimetiere P, Charles MA: The Three-Factor Eating Questionnaire-R18 is able to distinguish among different eating patterns in a general population. J Nutr 2004;134:2372-2380.
25 Karlsson J, Persson LO, Sjostrom L, Sullivan M: Psychometric properties and factor structure of the Three-Factor Eating Questionnaire (TFEQ) in obese men and women. Results from the Swedish Obese Subjects (SOS) study. Int J Obes Relat Metab Disord 2000;24:1715-1725.

26 Stunkard AJ, Messick S: The Three-Factor Eating Questionnaire to measure dietary restraint, disinhibition and hunger. J Psychosom Res 1985;29:71-83.

27 Franz MJ, Vanwormer JJ, Crain AL, Boucher JL, Histon T, Caplan W, Bowman JD, Pronk NP: Weight-loss outcomes: a systematic review and meta-analysis of weight-loss clinical trials with a minimum 1-year follow-up. J Am Diet Assoc 2007; 107:1755-1767.

28 Noar SM, Benac CN, Harris MS: Does tailoring matter? Meta-analytic review of tailored prin health behavior change interventions. Psychol Bull 2007:133:673-693.

29 Kruger J, Galuska DA, Serdula MK, Jones DA: Attempting to lose weight: specific practices among U.S. adults. Am J Prev Med 2004;26:402-406.

30 Levy AS, Heaton AW: Weight Control practices of U.S. adults trying to lose weight. Ann Intern Med 1993;119:661-666.

31 Skinner CS, Campbell MK, Rimer BK, Curry S, Prochaska JO: How effective is tailored print communication? Ann Behav Med 1999;21:290-298.

32 Rimer BK, Glassman B: Is there a use for tailored print communications in cancer risk communication? J Natl Cancer Inst Monogr 1999:140-148.

33 Wing RR, Hill JO: Successful weight loss maintenance. Annu Rev Nutr 2001;21:323-341.

34 Jeffery RW, Drewnowski A, Epstein LH, Stunkard AJ, Wilson GT, Wing RR, Hill DR: Long-term maintenance of weight loss: current status. Health Psychol 2000;19(1 suppl):5-16.

35 Beran MS, Fowles JB, Kind EA, Craft CE: State of the art reviews: patient and physician communication about weight management: can we close the gap? Am J Life Med 2008;2:75-83. 